\title{
Soluble Biobased Polyimides from Diaminotruxinic Acid with Unique Bending Angles
}

Takumi Noda, Takuma Iwasaki, Kenji Takada, and Tatsuo Kaneko*

Graduate School of Advanced Science and Technology, Japan Advanced Institute of Science and

Technology, 1-1 Asahidai, Nomi, Ishikawa, 923-1211, Japan.

CORRESPONDING AUTHOR FOOTNOTE

Tel: +81-761-51-1631. Fax: +81-761-51-1635. E-mail: kaneko@jaist.ac.jp 


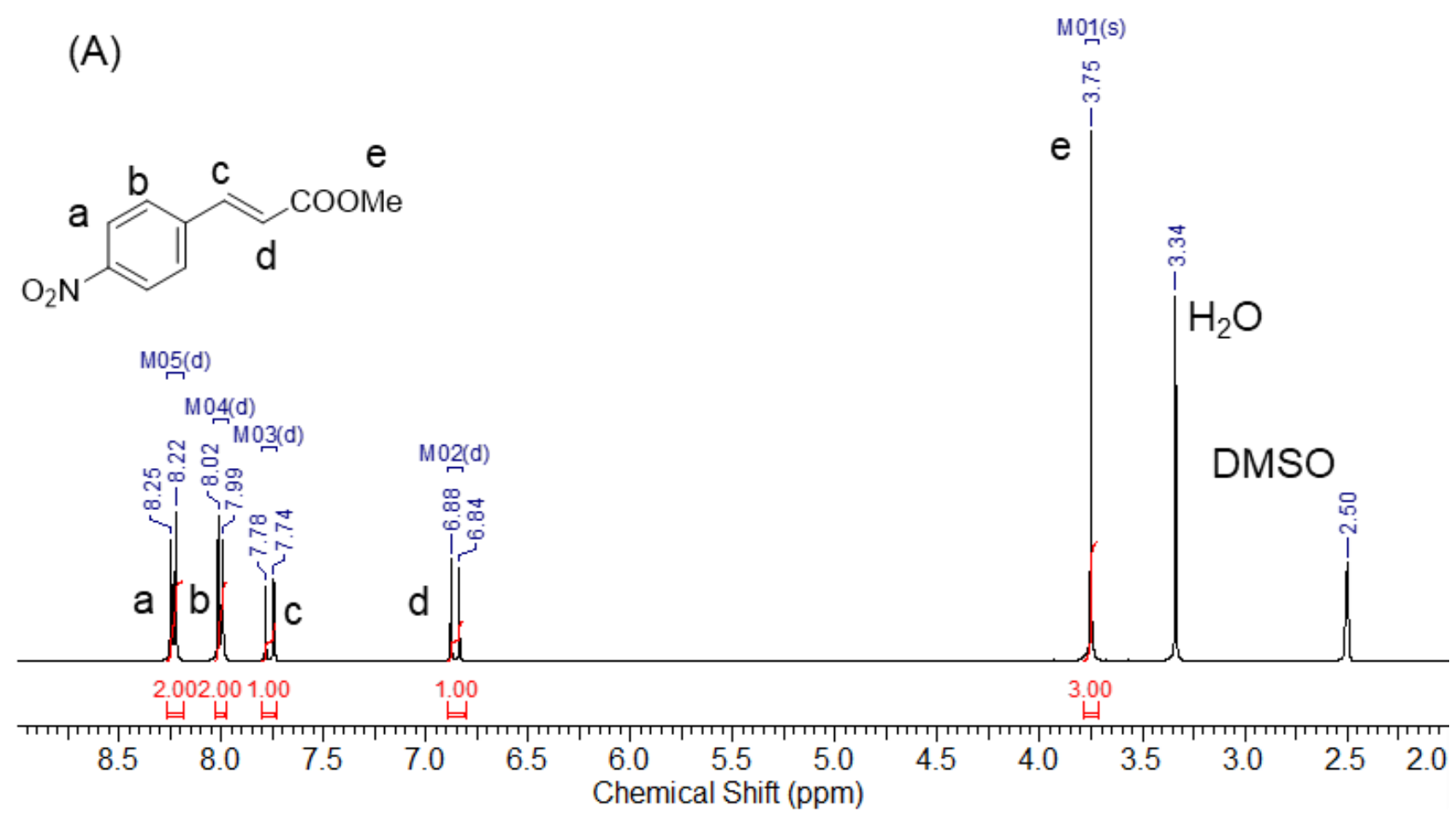

(B)<smiles>COC(=O)C=Cc1ccc([N+](=O)[O-])cc1</smiles>

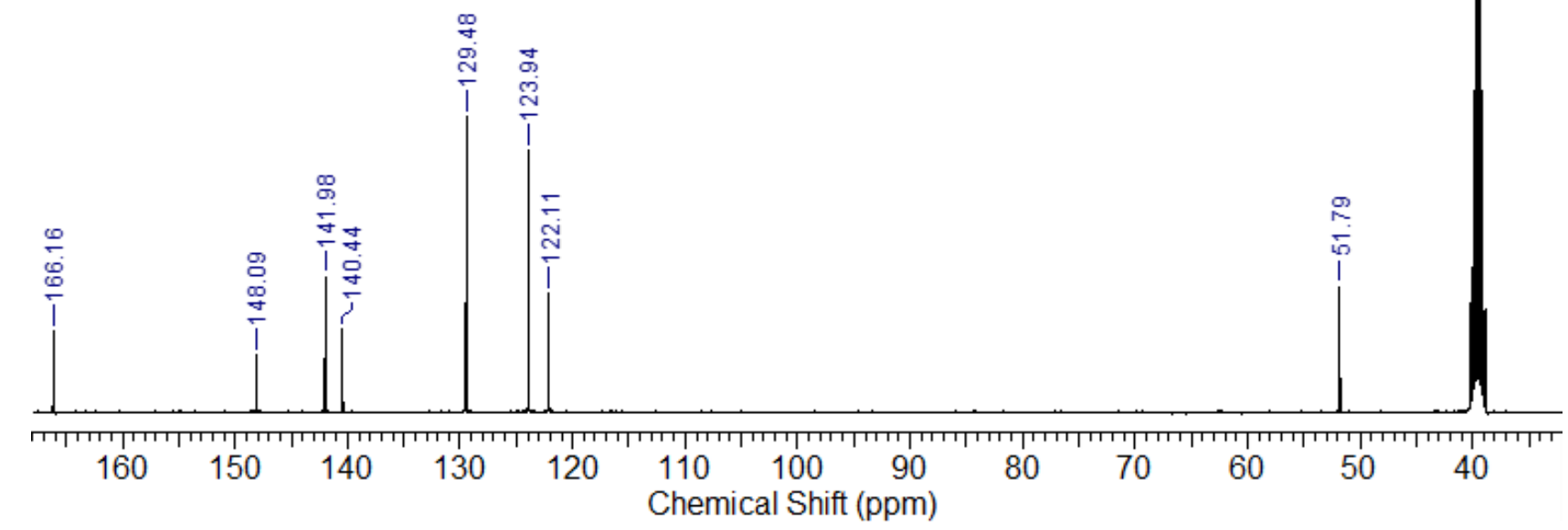

Figure S1. (A) ${ }^{1} \mathrm{H}$ NMR (400 MHz, DMSO- $\left.d_{6}\right)$ and (B) ${ }^{13} \mathrm{C}$ NMR (100 MHz, DMSO- $d_{6}$ ) spectra of 4NCA-Me. 


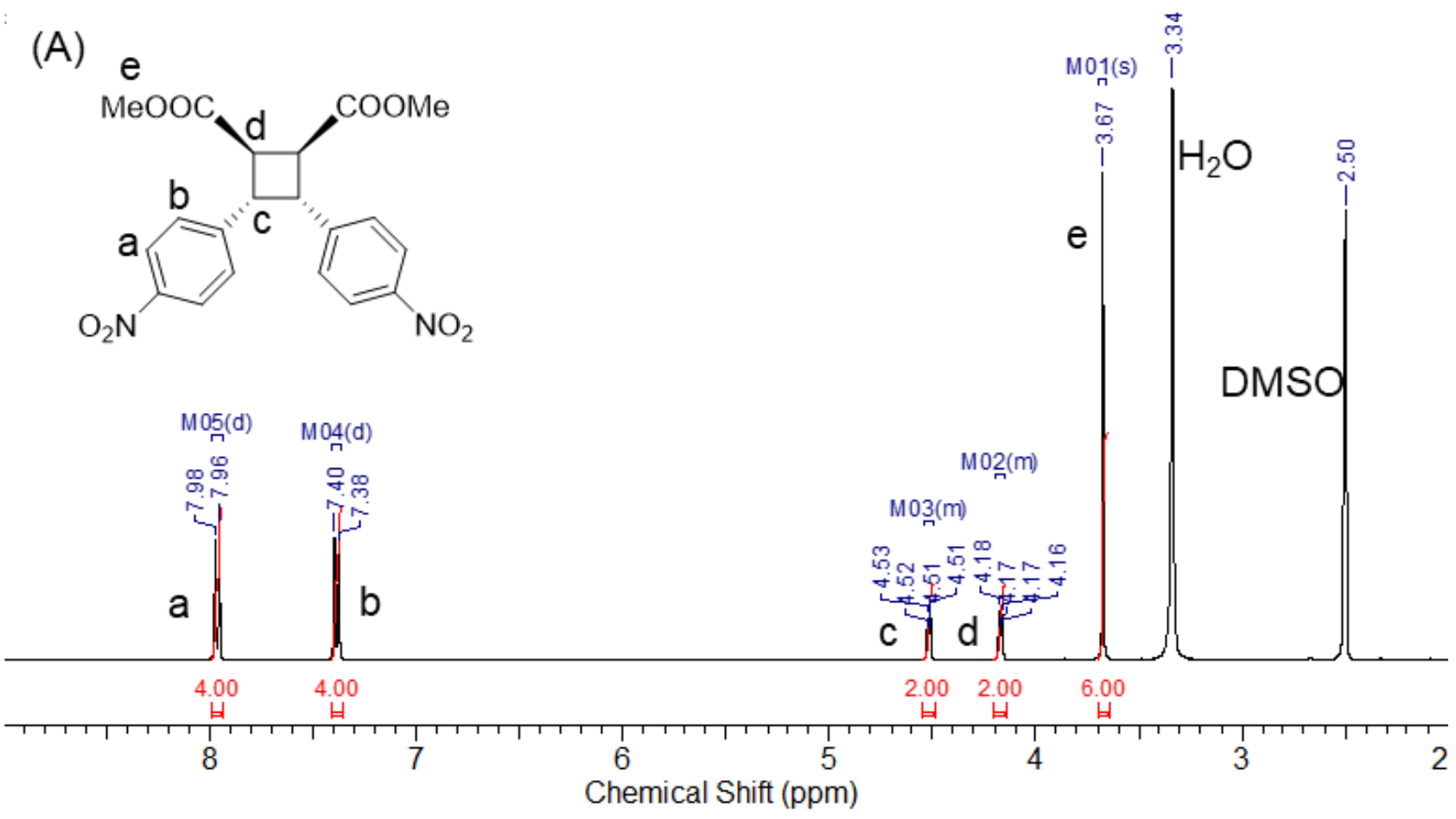

(B)
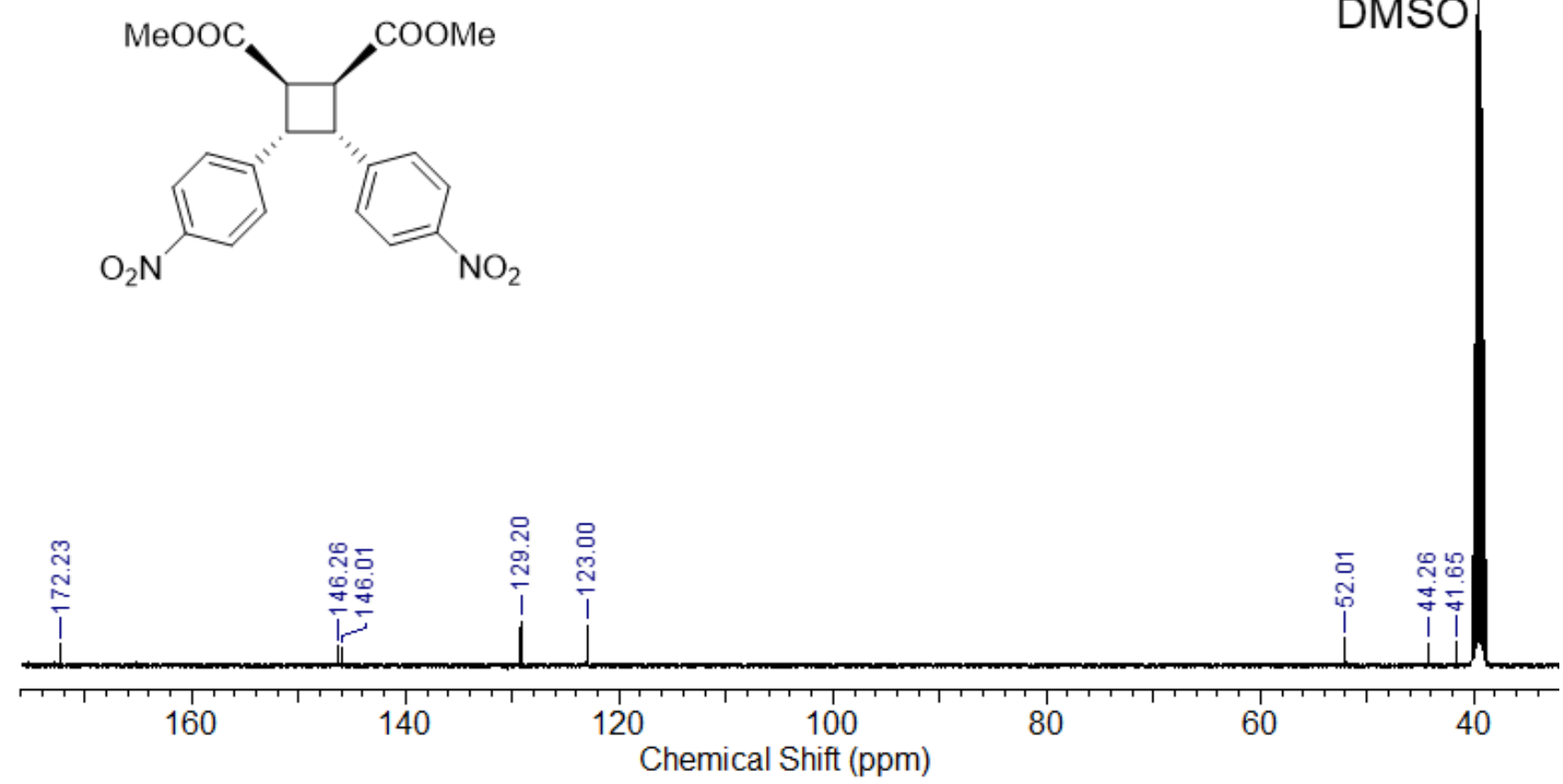

Figure S2. (A) ${ }^{1} \mathrm{H}$ NMR (400 MHz, DMSO- $d_{6}$ ) and (B) ${ }^{13} \mathrm{C}$ NMR (100 MHz, DMSO- $\left.d_{6}\right)$ spectra of $\beta$ NTA-Me. 
(A) $f$<smiles>COC(=O)C1C(C(=O)OC)[C@H](c2ccc(N)cc2)C1c1ccc(N)cc1</smiles>

M01(s)

M02(m)

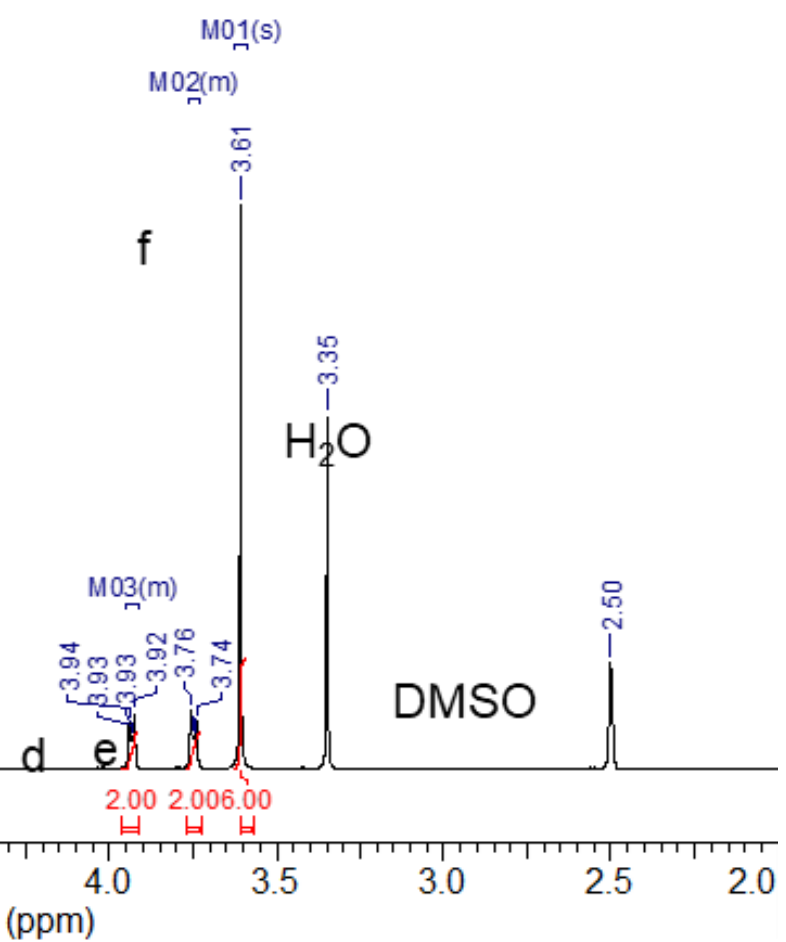

$\underset{706(d)}{\operatorname{M05}(d)}$

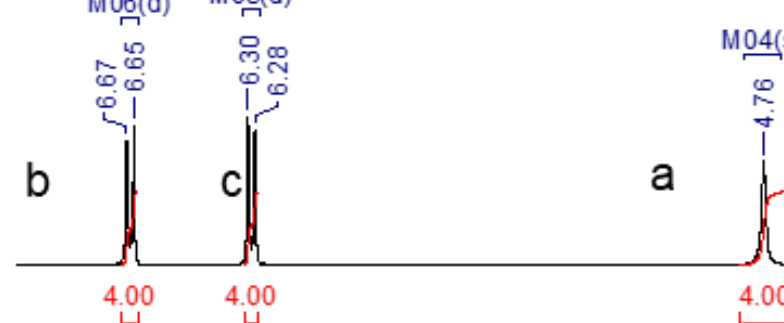

(B)
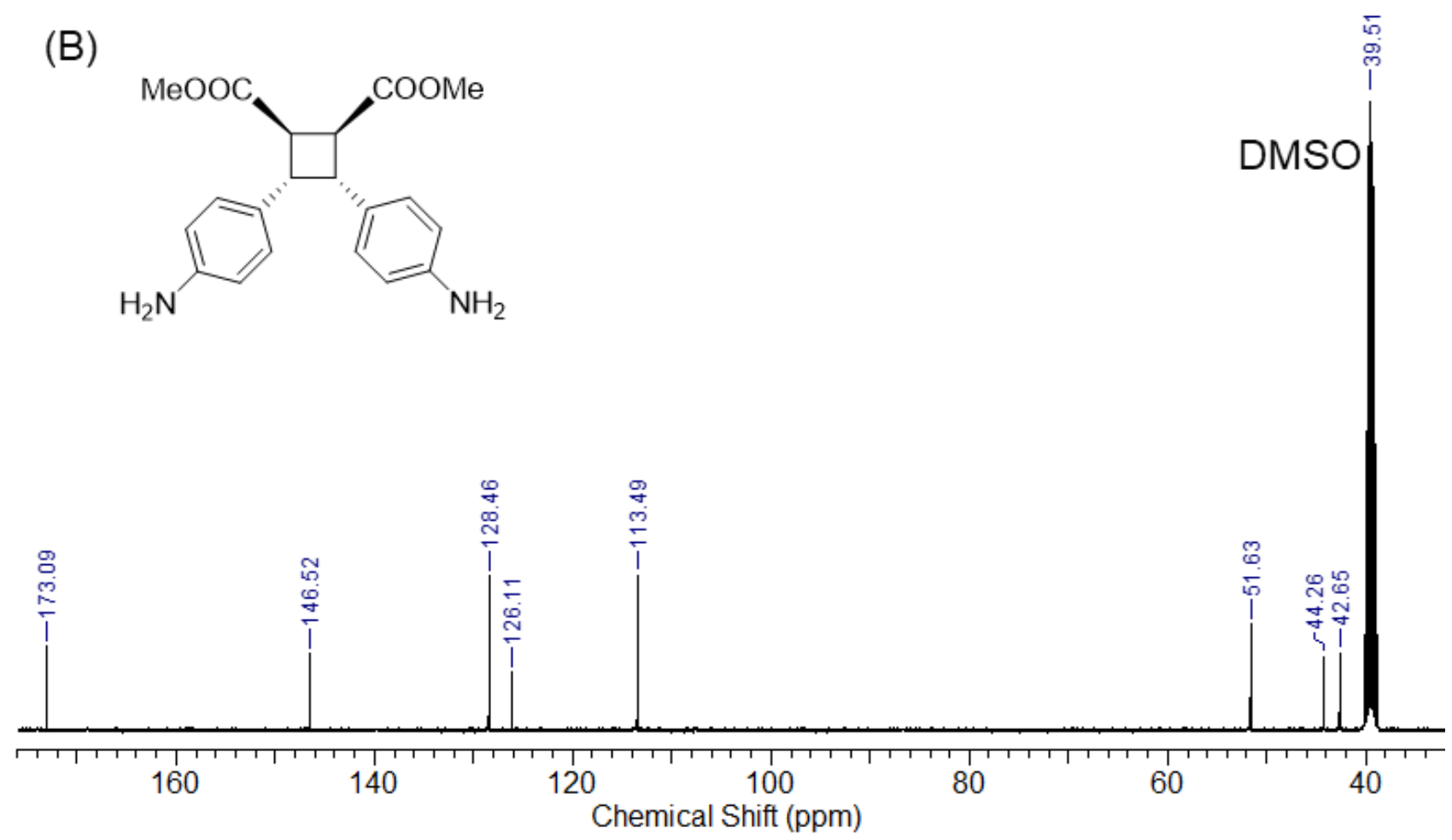

Figure S3. (A) ${ }^{1} \mathrm{H}$ NMR (400 MHz, DMSO- $\left.d_{6}\right)$ and (B) ${ }^{13} \mathrm{C}$ NMR (100 MHz, DMSO- $\left.d_{6}\right)$ spectra of $\beta$ ATA-Me. 
(A)

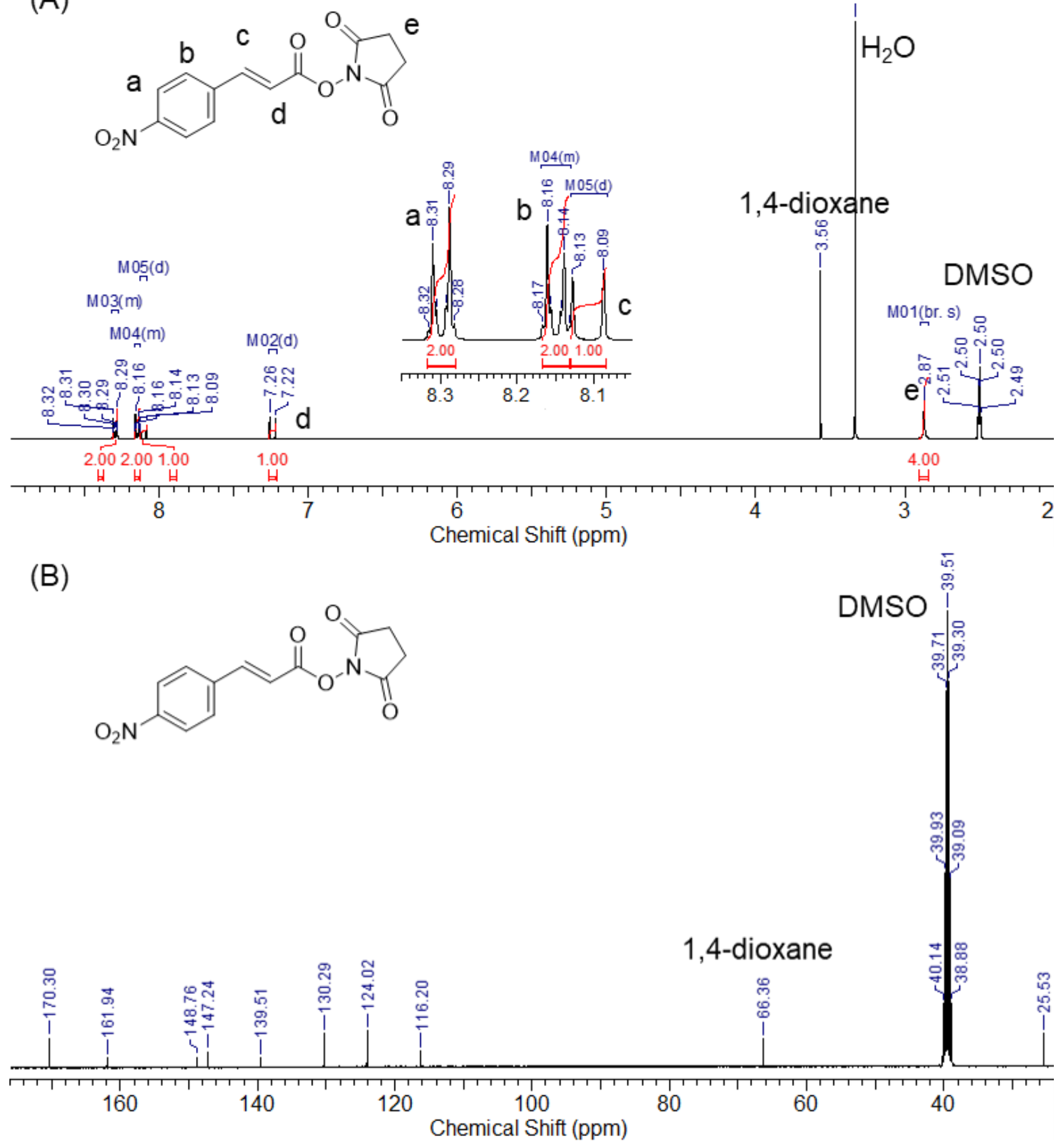

Figure S4. (A) ${ }^{1} \mathrm{H}$ NMR (400 MHz, DMSO- $\left.d_{6}\right)$ and (B) ${ }^{13} \mathrm{C}$ NMR (100 MHz, DMSO- $\left.d_{6}\right)$ spectra of 4NCA-NHS. 
(A)

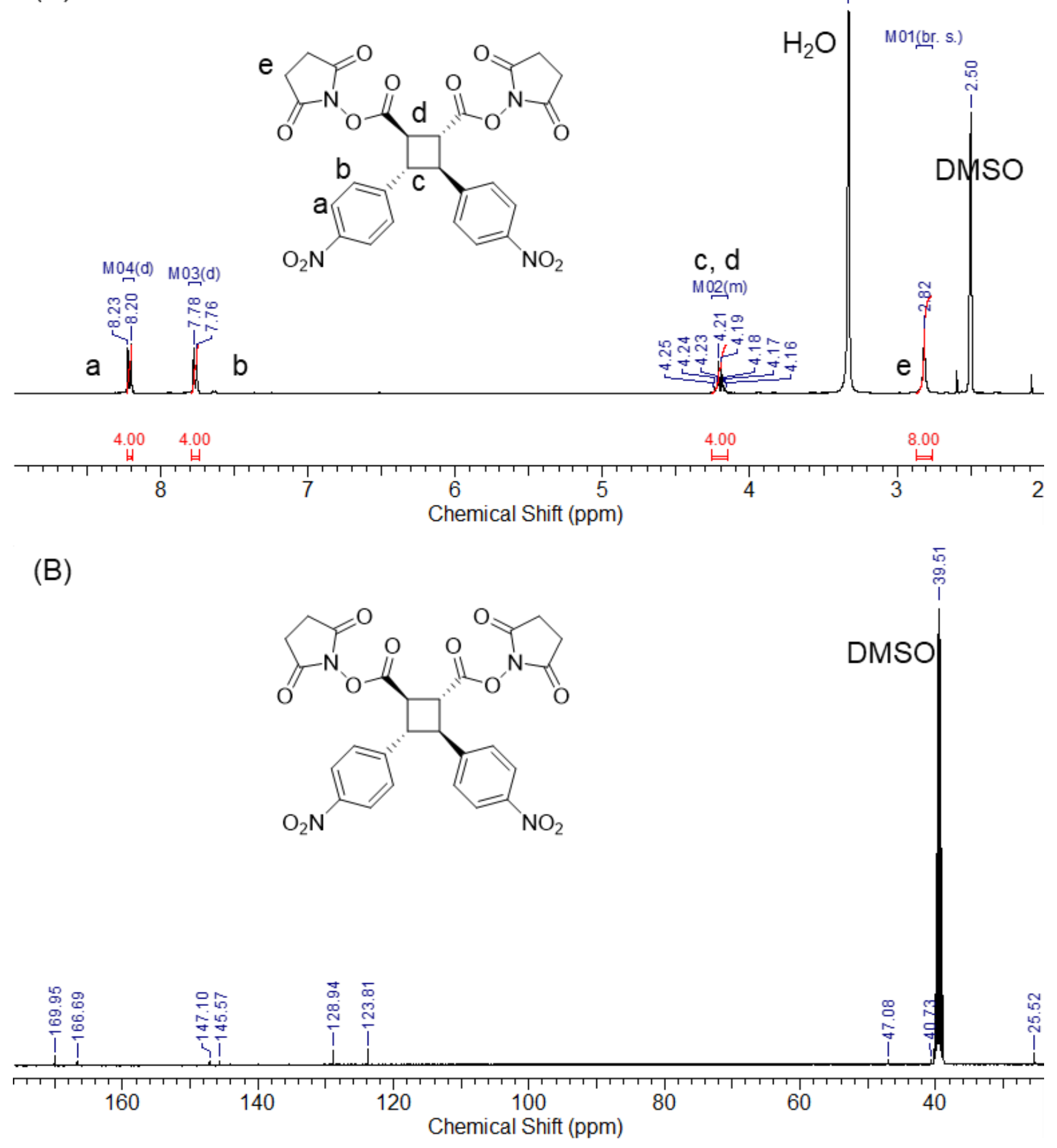

Figure S5. (A) ${ }^{1} \mathrm{H}$ NMR (400 MHz, DMSO- $\left.d_{6}\right)$ and (B) ${ }^{13} \mathrm{C}$ NMR (100 MHz, DMSO- $\left.d_{6}\right)$ spectra of $\delta$ NTA-NHS 
(A) $e$<smiles>COC(=O)C1C(C(C)=O)C(c2ccc([N+](=O)[O-])cc2)C1c1ccc([N+](=O)[O-])cc1</smiles>

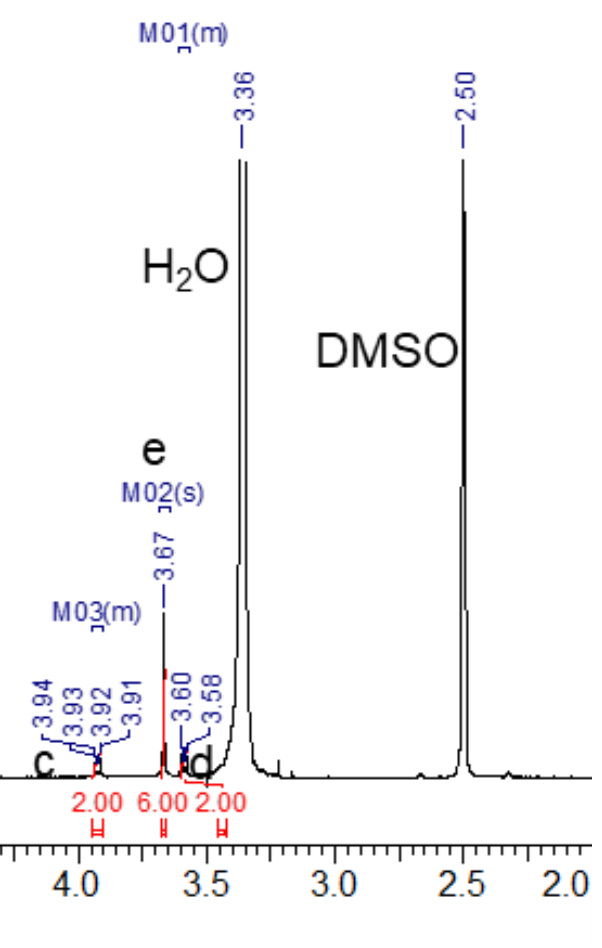

(B)<smiles>COC(=O)[C@H]1[C@@H](C(C)=O)[C@@H](c2ccc([N+](=O)[O-])cc2)[C@H]1c1ccc([N+](=O)[O-])cc1</smiles>
DMSO

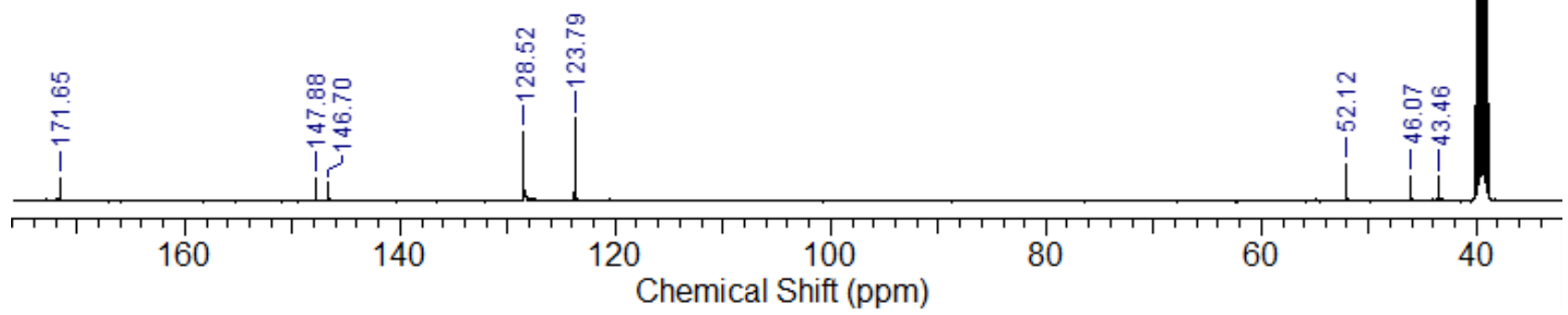

Figure S6. (A) ${ }^{1} \mathrm{H}$ NMR (400 MHz, DMSO- $d_{6}$ ) and (B) ${ }^{13} \mathrm{C}$ NMR (100 MHz, DMSO- $\left.d_{6}\right)$ spectra of $\delta$ NTA-Me. 
(A)
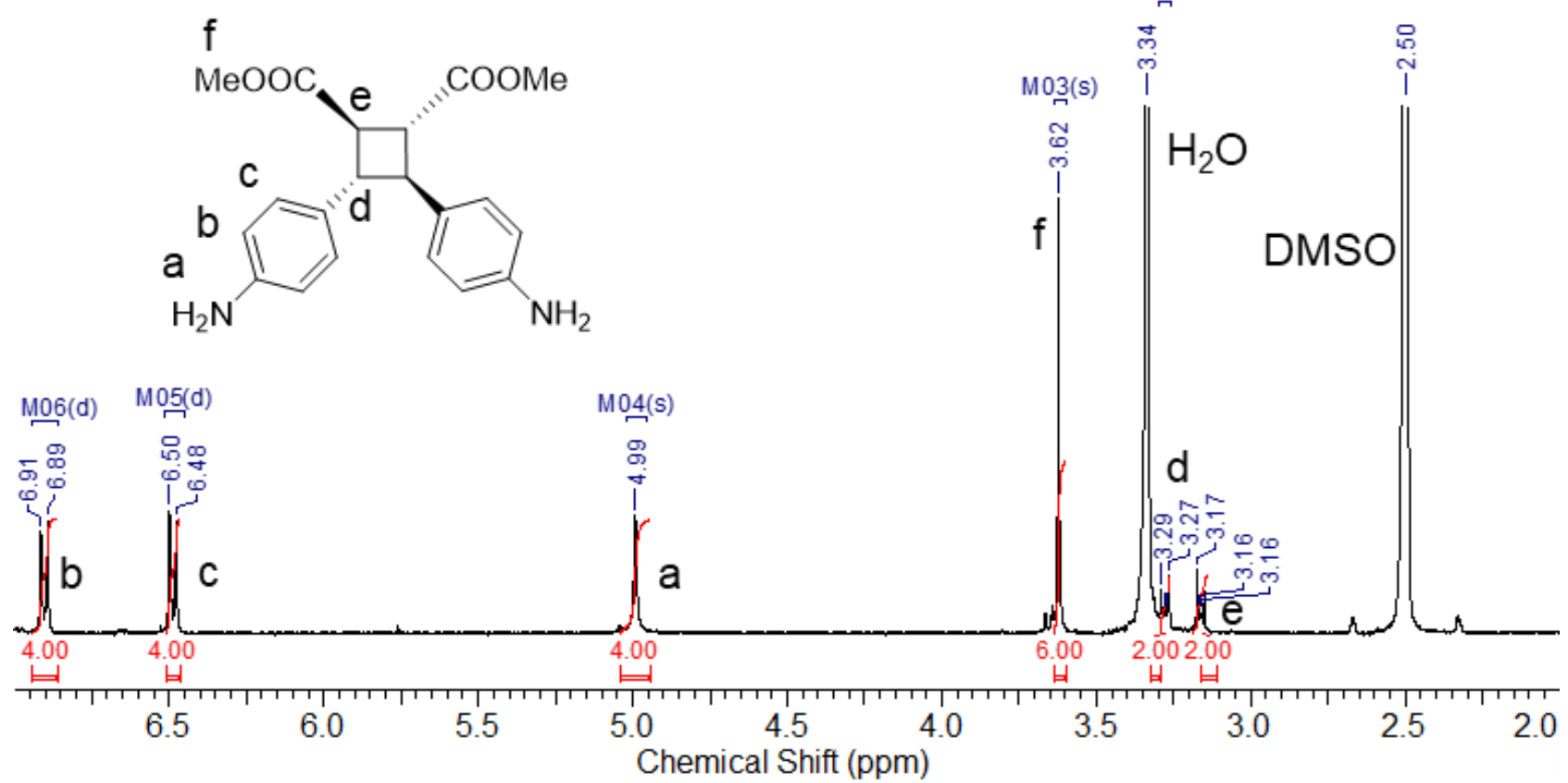

(B)
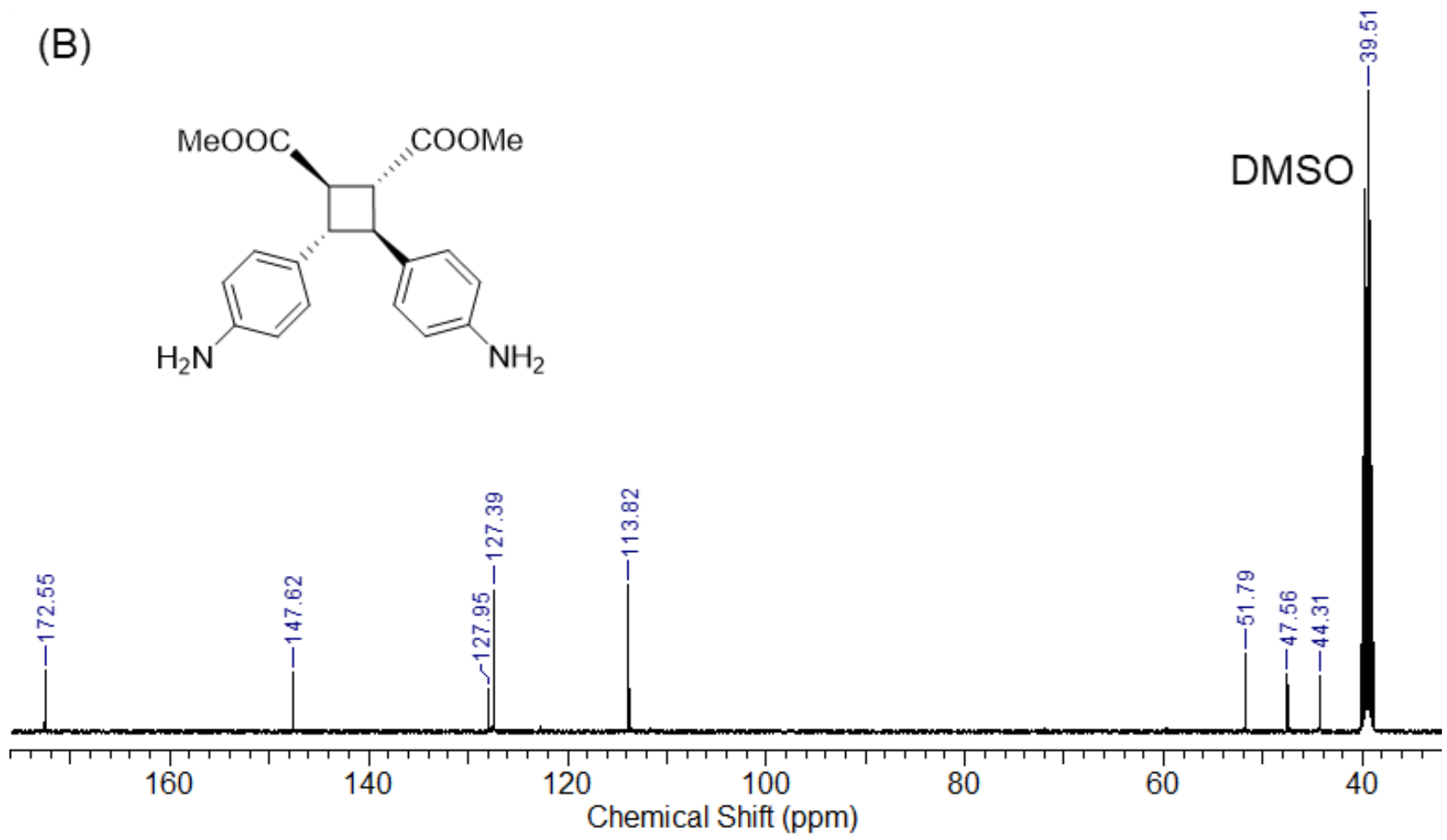

Figure S7. (A) ${ }^{1} \mathrm{H}$ NMR (400 MHz, DMSO- $d_{6}$ ) and (B) ${ }^{13} \mathrm{C}$ NMR (100 MHz, DMSO- $\left.d_{6}\right)$ spectra of $\delta$ ATA-Me. 


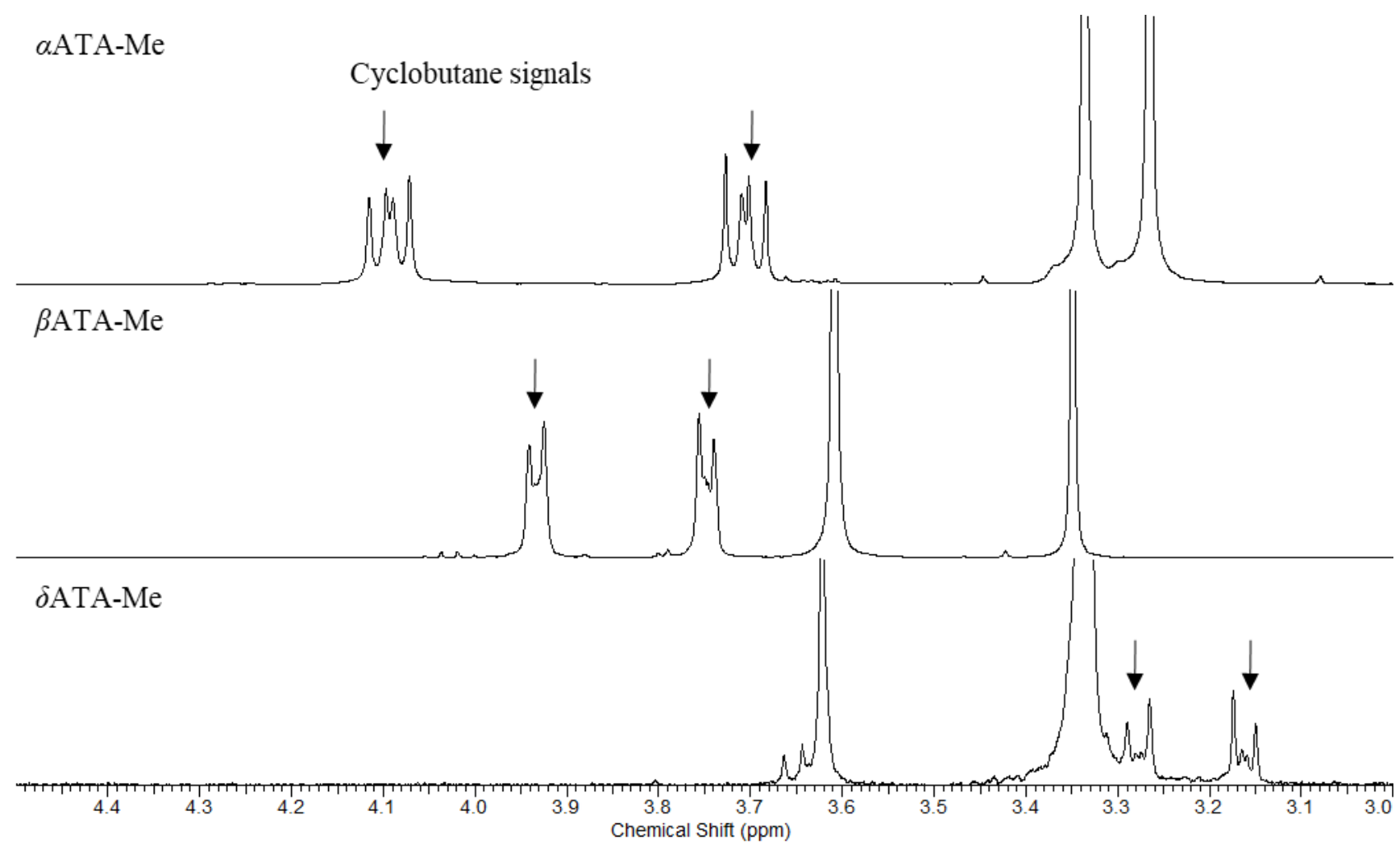

Figure S8. ${ }^{1} \mathrm{H}$ NMR (400 MHz, DMSO- $d_{6}$ ) spectra of isomeric 4-aminocinnamte photodimer-based diamines. 
(a)

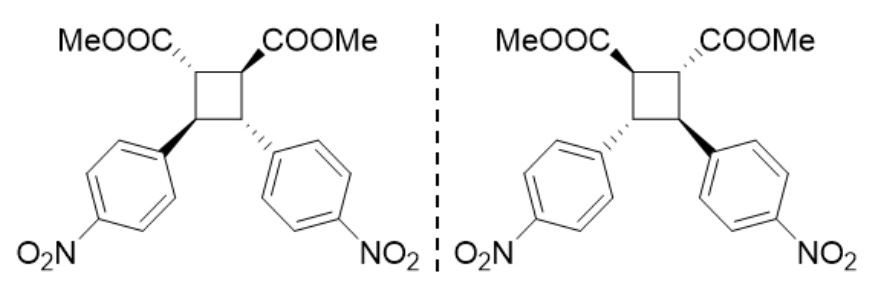

(b)

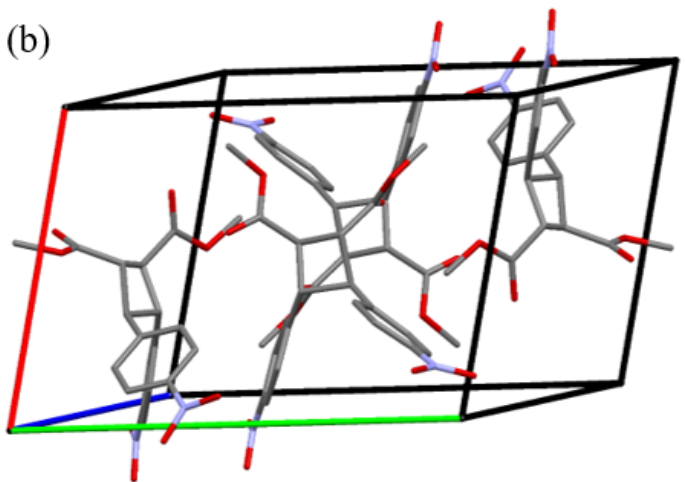

Figure S9. (a) Enantiomers of the $\delta$ NTA-Me, (b) crystal packing of $\delta$ NTA-Me.

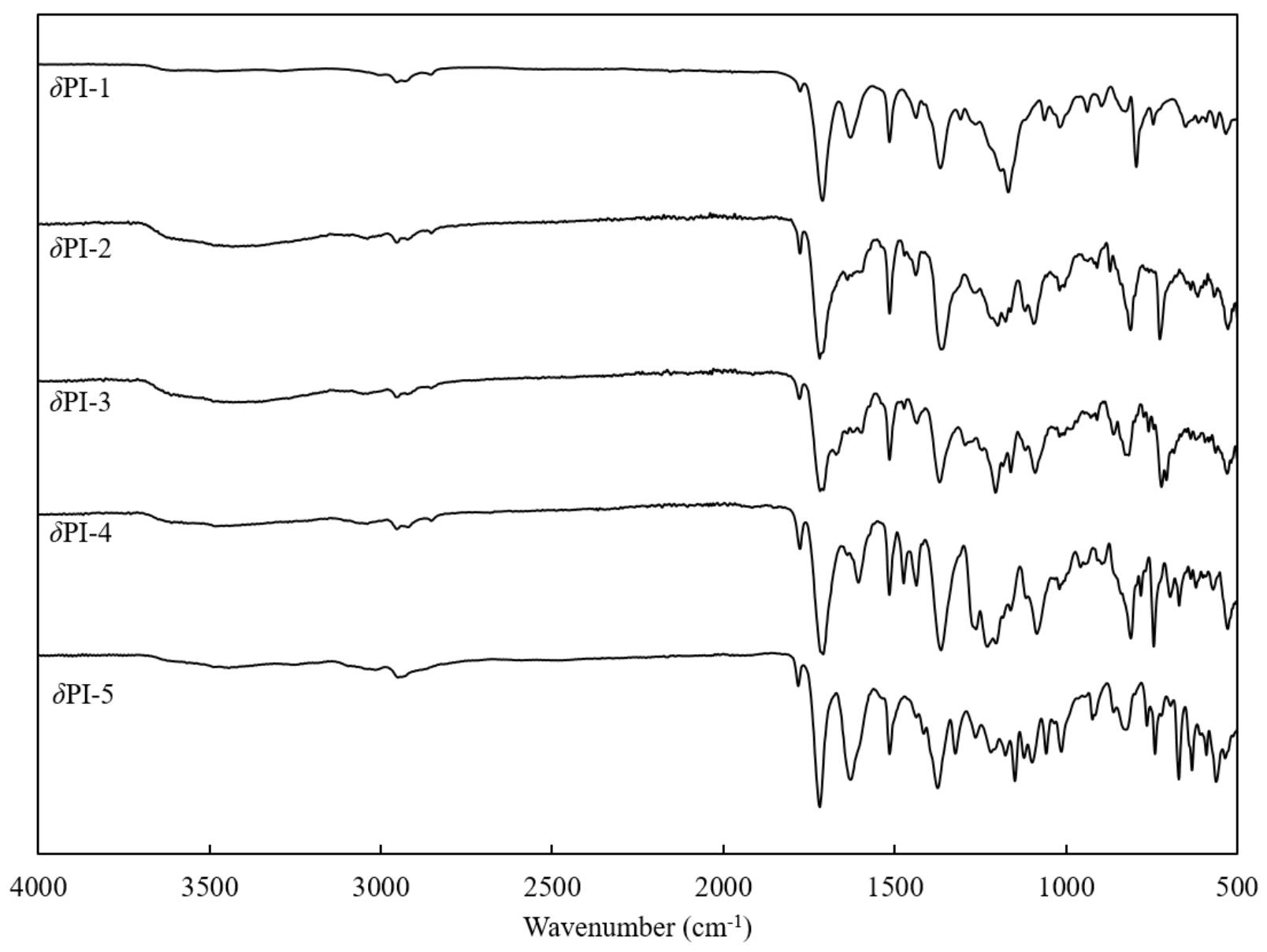

Figure S10. IR spectra of the $\delta$ PIs. 


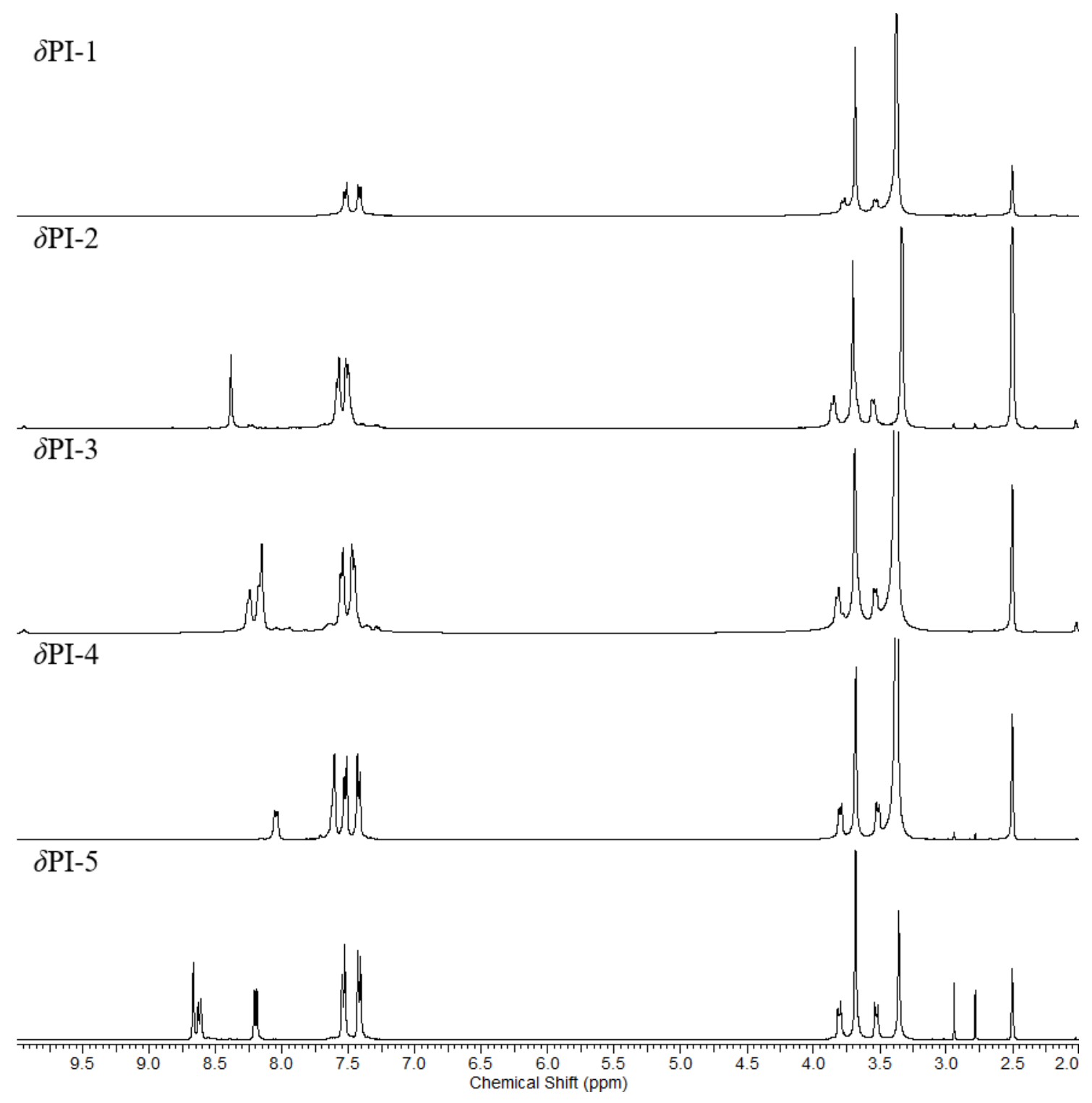

Figure S11. ${ }^{1} \mathrm{H}$ NMR $\left(400 \mathrm{MHz}, \mathrm{DMSO}-d_{6}\right)$ spectra of $\delta$ PIs. 


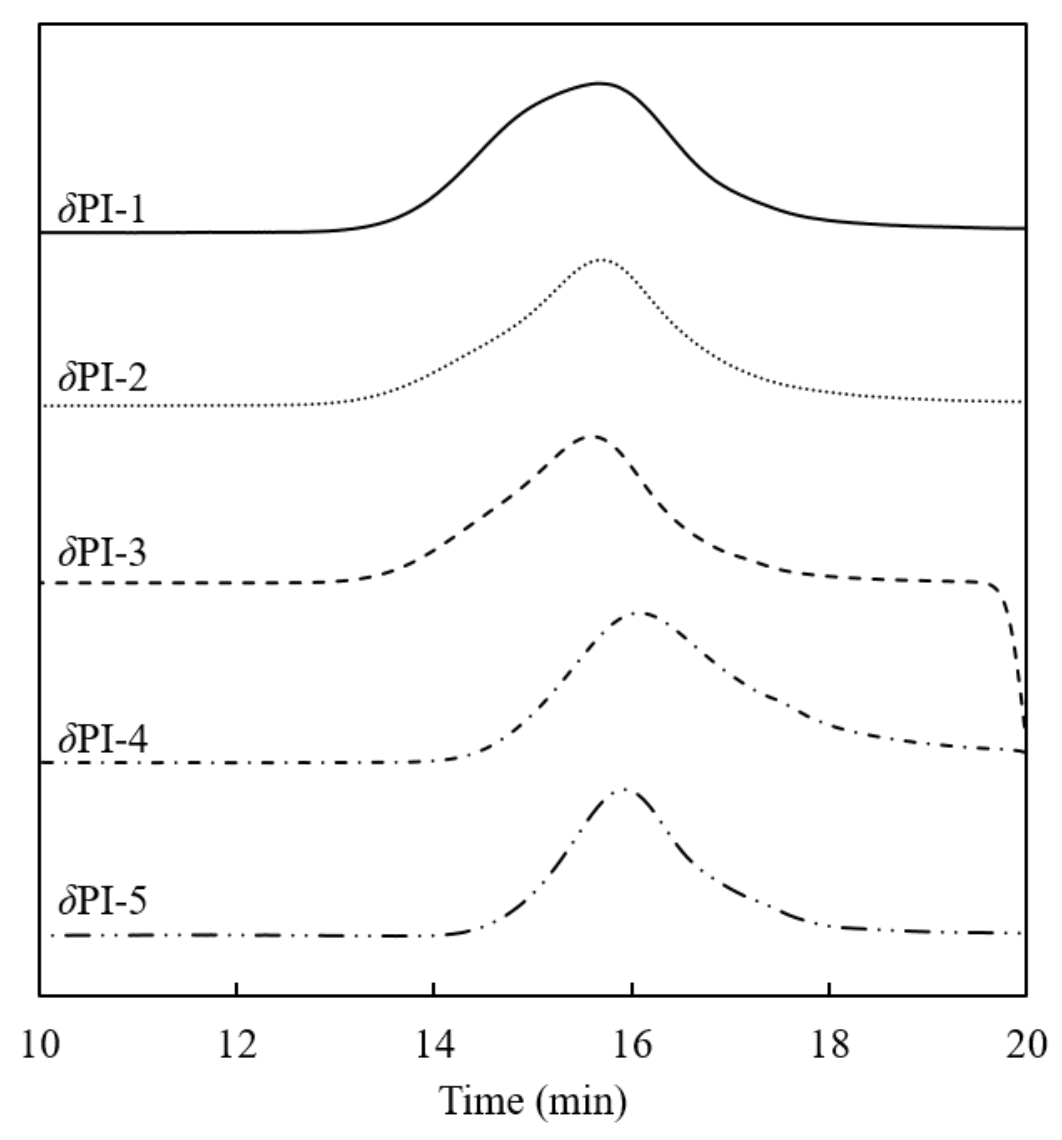

Figure S12. SEC traces of the $\delta$ PIs (solvent, DMF containing $0.01 \mathrm{~mol} / \mathrm{L}$ of $\mathrm{LiBr}$; flow rate, 1.0 $\mathrm{mL} / \mathrm{min}$ ). 


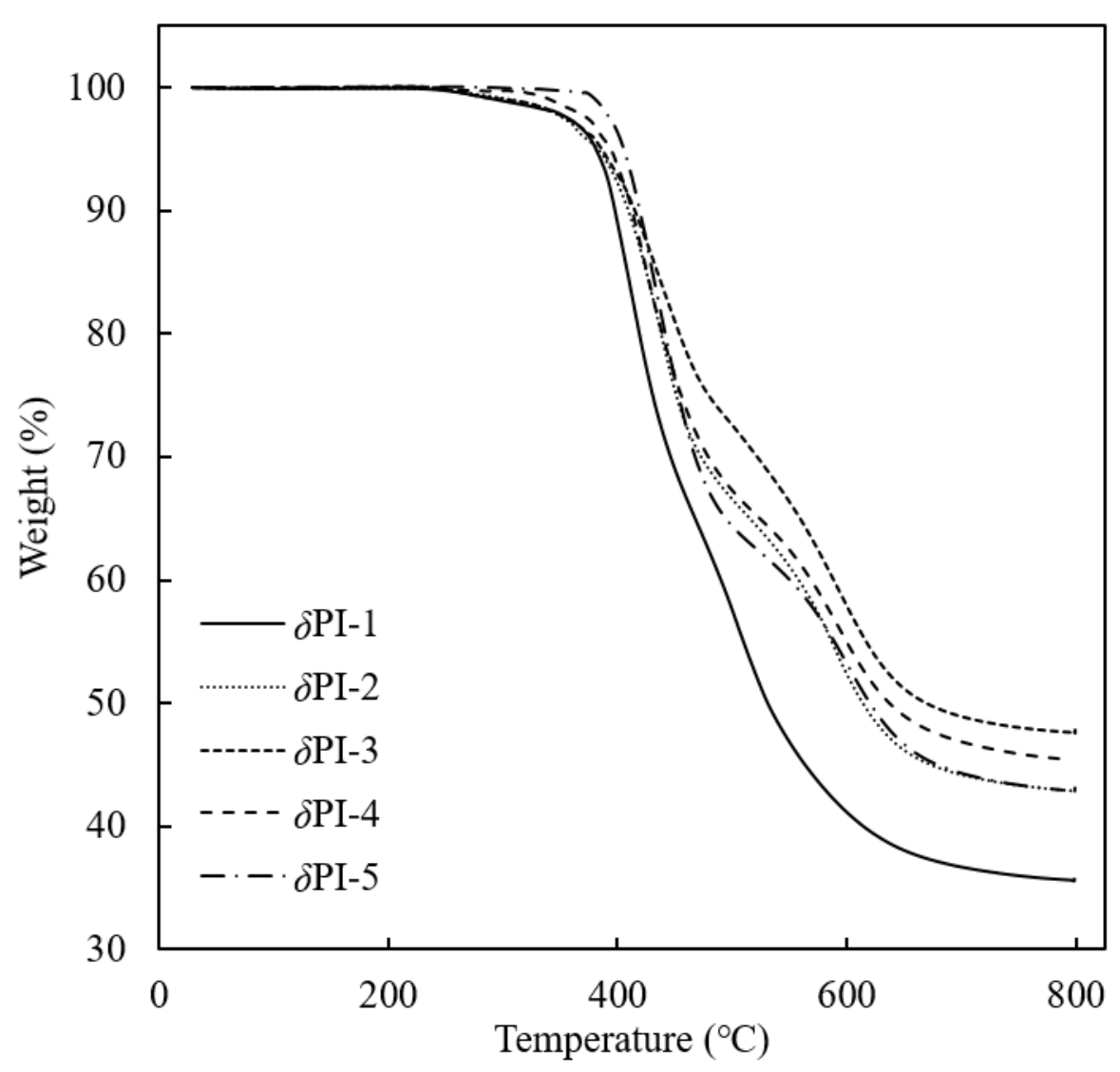

Figure S13. TGA curves of $\delta$ PIs. 


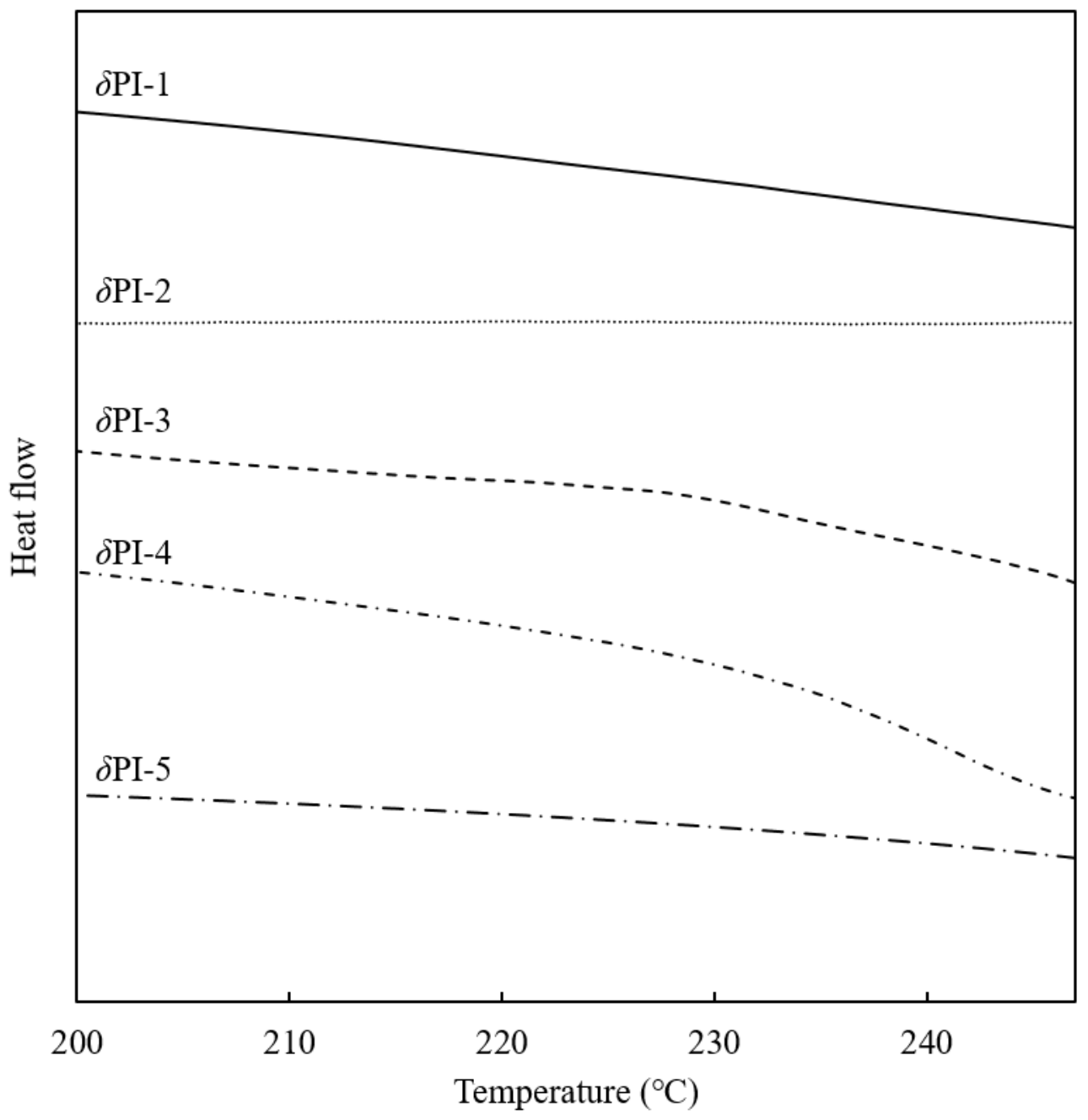

Figure S14. DSC curves of $\delta$ PIs. 


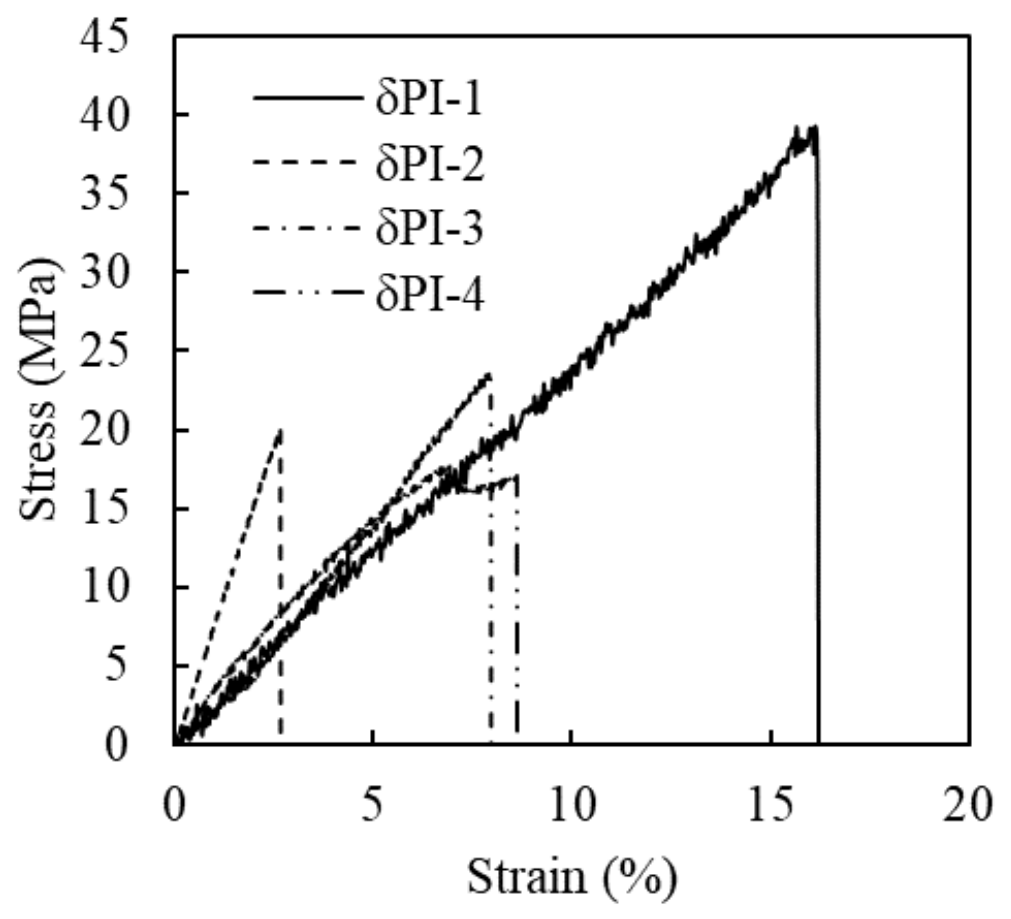

Figure S15. Stress-strain curves of $\delta$ PIs.

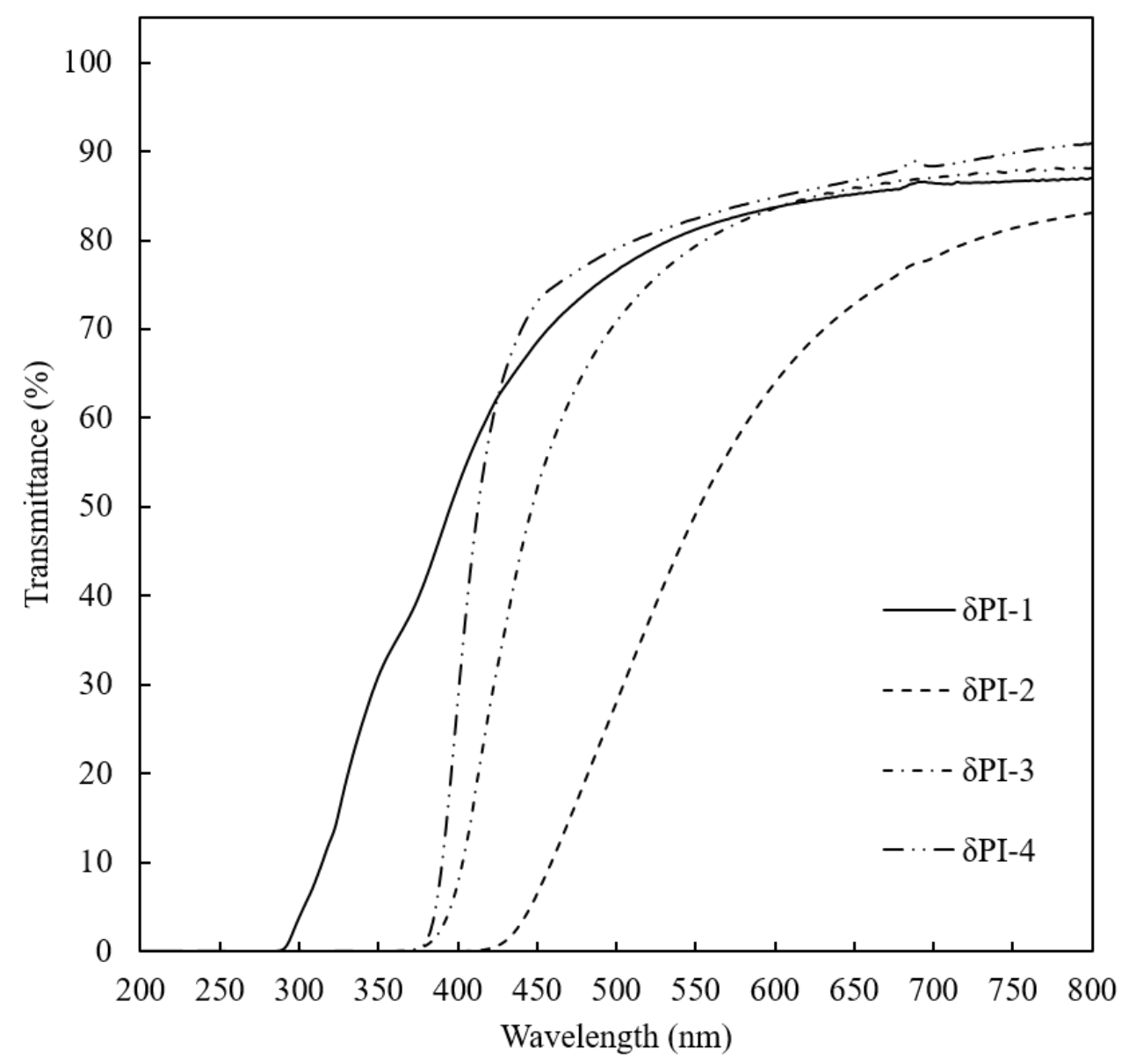

Figure S16. UV-vis absorption spectra of $\delta$ PIs. 